\title{
Calculating an EDS Spectrum without Scatter in LV Mode
}

\author{
R. Anderhalt, L.M. Swenson \\ EDAX Inc., 91 McKee Drive, Mahwah, NJ 07430
}

EDS analysis of features is commonly accomplished using low vacuum or ESEM conditions. The spectrum will consist of $\mathrm{x}$ rays that are derived from the feature of interest from the unscattered electron beam as well as from the area that surrounds the feature of interest from electrons that have scattered from the primary beam after a collision with a gas molecule. The scattered beam may create $\mathrm{x}$ rays from distances of several millimeters from the sample. The job of the analyst to interpret the composition of the feature of interest is made more difficult because it becomes necessary to determine which elements in the spectrum are truly from the feature itself and which elements are from the surrounding area.

A polished rock sample was imaged with the BSE detector in low vacuum mode at a variety of pressures (Fig. 1a). A mineral grain was selected to collect a spectrum at $20 \mathrm{~Pa}$ as well as $40 \mathrm{~Pa}$ (Fig. 1b). Previously, a spectrum was collected of the same grain under high vacuum conditions and the elements present in this grain were confirmed to be $\mathrm{O}, \mathrm{F}, \mathrm{P}$, and $\mathrm{Ca}$ (fluor-apatite). The area surrounding the grain tended to be rich in $\mathrm{Si}, \mathrm{Al}, \mathrm{K}, \mathrm{Na}, \mathrm{Ca}$ and $\mathrm{O}$. Elements that were not present in the grain or feature of interest ( $\mathrm{Na}, \mathrm{Al}$, and $\mathrm{Si}$; also $\mathrm{K}$ which is not shown in Fig. 1b) were highest in the $40 \mathrm{~Pa}$ spectrum and the peak size or peak area are roughly twice that of the $20 \mathrm{~Pa}$ spectrum (Fig. 1b).

A method was proposed by Doehne [1] to calculate a spectrum which eliminates the effect of scattering outside the feature of interest. It required one spectrum to be acquired at twice the pressure of another and involved an additional empirical multiplier of the differences in the channel intensities of the two spectra. In our case, the two spectra are normalized to a background region which eliminates the need for the empirical factor. It is commonly observed that the higher pressure spectrum will have a lower count rate. It is tempting to create an equivalent count rate by adjusting the spot size but the normalization procedure appears to eliminate that need as well.

In Fig. 2 a spectrum is shown which resulted from multiplying the $20 \mathrm{~Pa}$ spectrum by 2 and subtracting the channel intensities of the $40 \mathrm{~Pa}$ spectrum (basically, the Doehne equation without the empirical factor). This calculated spectrum effectively eliminates the elements that are present in the scatter region but not in the feature of interest. Although the chemistry of the feature and the scatter region are moderately complex and varied, this method appears to be valid.

Other pressure combinations produce similar results (e.g. 10 and $20 \mathrm{~Pa}, 30$ and $60 \mathrm{~Pa}$, and 40 and 80 $\mathrm{Pa}$ ). The pressures selected, however, should be high enough to assure the lack of charging effects in the image and in the spectrum.

References

[1] E. Doehne. Scanning. 19 (1997) 75-78. 

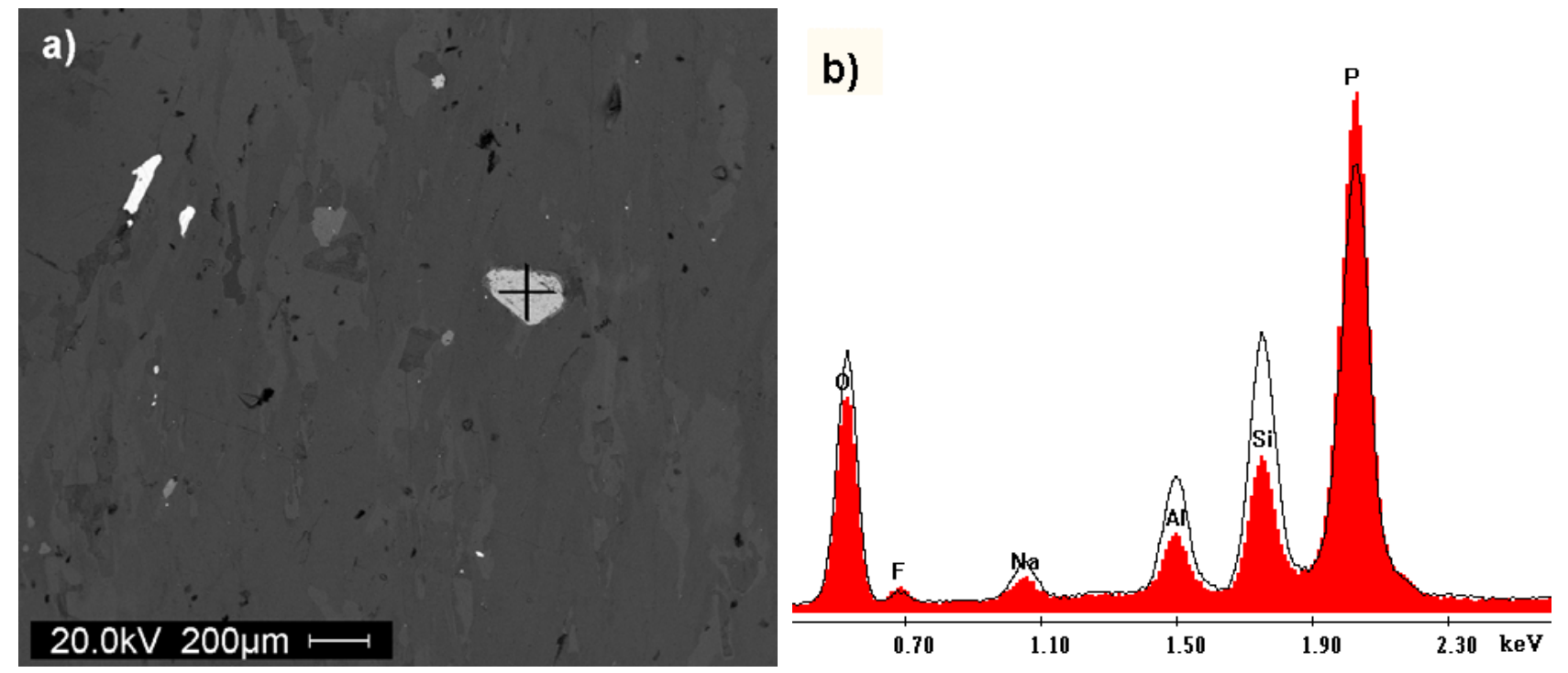

FIG. 1a. BSE image (on the left) of a silicate-rich rock. The "+" on the image shows the location of the spectra collected.

FIG. 1b. Spectra collected at $20 \mathrm{~Pa}$ and $40 \mathrm{~Pa}$. The $20 \mathrm{~Pa}$ spectrum is shown as a solid red spectrum and the $40 \mathrm{~Pa}$ spectrum is shown as a black line.

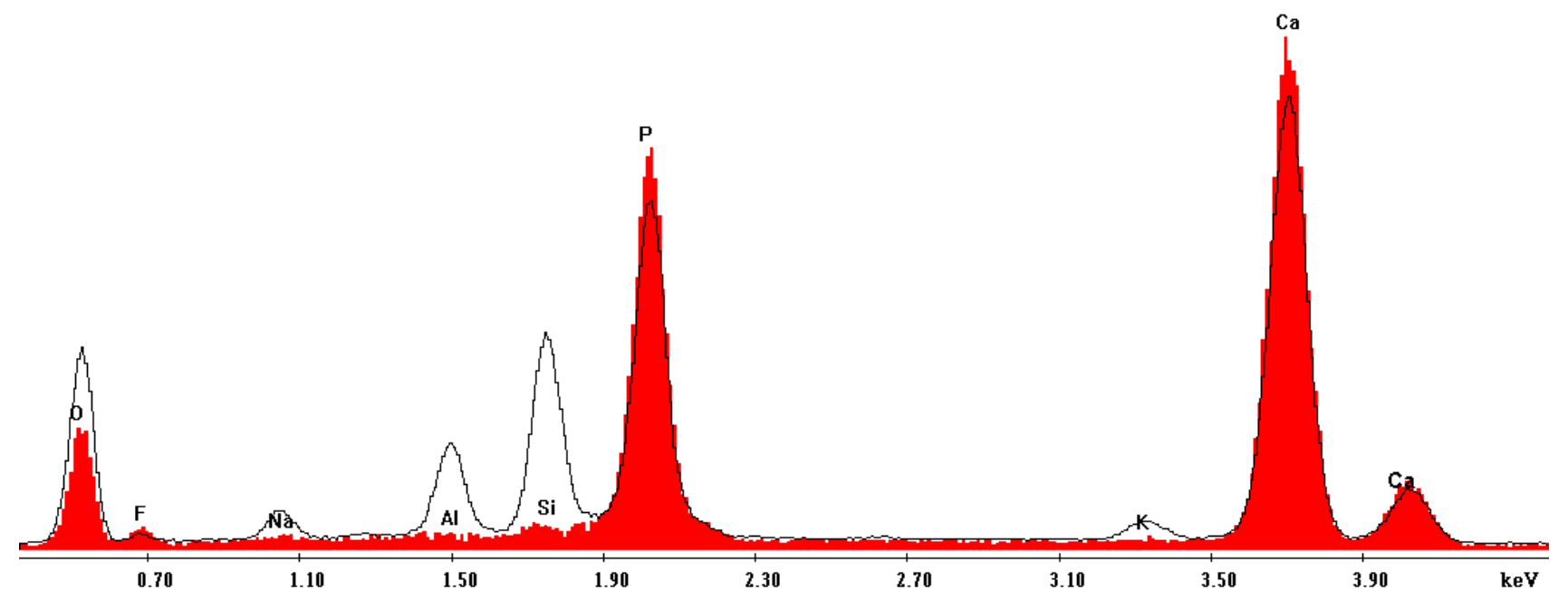

FIG. 2. A calculated spectrum shown in red and overlain with the $40 \mathrm{~Pa}$ spectrum (black line). The calculated spectrum was derived from the difference between $2 \mathrm{x}$ the $20 \mathrm{~Pa}$ spectrum and the $40 \mathrm{~Pa}$ spectrum. Note that the $\mathrm{Na}, \mathrm{Al}, \mathrm{Si}$ and $\mathrm{K}$ peak are not present in the calculated spectrum. 